\title{
The Analysis of Schedule Control of Construction Project Using AHP Methods
}

\author{
Ke Liu ${ }^{1, a, *}$ \\ ${ }^{1}$ Complete Project Research, Logistics University of Chinese People’s Armed Police Force, Tianjin, China \\ a502335602@qq.com \\ *corresponding author
}

Keywords: AHP, influence factor, weight coefficient, AHP

\begin{abstract}
The schedule control is a method which keep the tasks, resources and time balanced to achieve project's goal. And with the development of the construction,the time limit for a project control has become more important than ever before. The article uses Analytic Hierarchy Process (AHP) method to find the most important factors, and table some proposals. The article presents 8 indexes of schedule control. This indexes were related to the design or construction: the accuracy of designs, reduce design changes, discussion of drawing,design plan. And in the aspect of the construction, construction preparation, construction plan, construction management and construction goal. Due to the analysis of the indexes, the article draw a conclusion that which indexes were more important than the others. The results of the analysis can be guiding plan. And the article provide the method in schedule control. The results can be successfully adapted in the work.
\end{abstract}

\section{Introduction}

The construction industry of China is playing an important role in our economy and social progress. The schedule control is one of the most important goals in the construction, and has relationship with the quality control and invest control. Since the China's reform and opening construction industry has developing and flourishing alone with the rapid development of national economy. More and more large-scale and high-tech construction projects, such as underground rail traffic, cross-sea bridge and skyscraper, has appeared. we were on the processing of construction into a huge human, financial strength and resources. If there would be some mistakes, we must afford very significant cost. We have to use scientific evaluation method to find the key factors to help us to plan for mistakes and loss. The AHP method is used to evaluate the significance of the index. This method is going to be used as a tool in ensuring the scientificity of the results.

\section{Description of the method}

Analytic Hierarchy Process (AHP) came from Dr. T. L. Saaty in 1970s. It is an effective method in the management. In the process of doing this method, the goal was devided into criterion layer and project layer. The AHP method is suitable to the Multi objective decision making, especial. When the decision influenced by multiple factors, and the elements, or there is a clear classification, at the same time, the influence degree of each index for final evaluation can not directly through enough data for quantitative calculation.

\subsection{The structure of AHP model}

Decision makers usually break down complex problems into several levels and several factors, often divided into three levels, which are the goal, the criterion, and the project layer. By simply comparing and calculating each factor, the weight of different schemes can be obtained, and the result can provid the basis for optimal selection.

In this method, the relationship between various factors in the analysis system is made to compare the importance of the same level of chromium elements to a certain criterion in the upper 
level, and then we can construct the comparison matrix.

If $n$ elements are involved in the comparison, then $A=\left(a_{i j}\right) n \times n$ becomes a pair comparison matrix. In pairs comparison matrix, the values of $a_{i j}$ can be evaluated in the following scale. $a_{i j}$ is between the reciprocal of 1-9.

$\alpha_{i j}=1$, Element $\mathrm{i}$ is just as important as element $\mathrm{j}$;

$a_{i j}=3$, Element $i$ is slightly more important than element $j$;

$\alpha_{i j}=5$, Element I is more important than element j;

$a_{i j}=7$, Element $i$ is more and more important than element $j$;

$a_{i j}=9$, Element $\mathrm{i}$ is extremely important than element $\mathrm{j}$;

$\alpha_{i j}=2 n, n=1,2,3,4$,The importance of element I and element $j$ is between $x$ and $x$;

$a_{i j}=\frac{1}{n}, n=1,2, \cdots, 9, a_{i j}=n$.

In pairs comparison matrix:

$a_{i j}>0, a_{i j}=1, a_{i j}=\frac{1}{a_{i j}}$

If $\mathrm{i}=\mathrm{j}, \mathrm{a}_{\mathrm{ij}}=1$.

Then we calculate the consistency of a pair matrix, the measure of the inconsistency of A (n>1).

$$
C I=\frac{\lambda_{\max }(\mathrm{A})-\mathrm{n}}{n-1}
$$

Then we The random consistency ratio of the comparison matrix.

$$
C R=\frac{C I}{R I}
$$

If $\mathrm{CR}<0.1$, It is acceptable to decide that the comparison matrix is satisfactory, or its inconsistency is acceptable. Otherwise, adjust the comparison matrix until the satisfied consistency is reached.

In this model, "Schedule Control(A)" is the goal. In time,the whole process of the schedule control can be divided into two phases: "Design $\left(\mathrm{B}_{1}\right)$ " and "construction( $\left(\mathrm{B}_{2}\right)$ ", that is called criterion. In the aspect of the design, it can be devided into "the accuracy of designs $\left(\mathrm{C}_{1}\right)$ ", "reduce design changes $\left(\mathrm{C}_{2}\right)$ ", "discussion of drawing $\left(\mathrm{C}_{3}\right)$ " and "design plan $\left(\mathrm{C}_{4}\right)$ ". And in the aspect of the construction, it can be devided into "construction preparation $\left(\mathrm{C}_{5}\right)$ ", "construction plan $\left(\mathrm{C}_{6}\right)$ ", "construction management $\left(\mathrm{C}_{7}\right)$ " and "construction goal $\left(\mathrm{C}_{8}\right)$ ". Figure 1 is the hierarchical structure of the evaluation of the progress of the accounts.

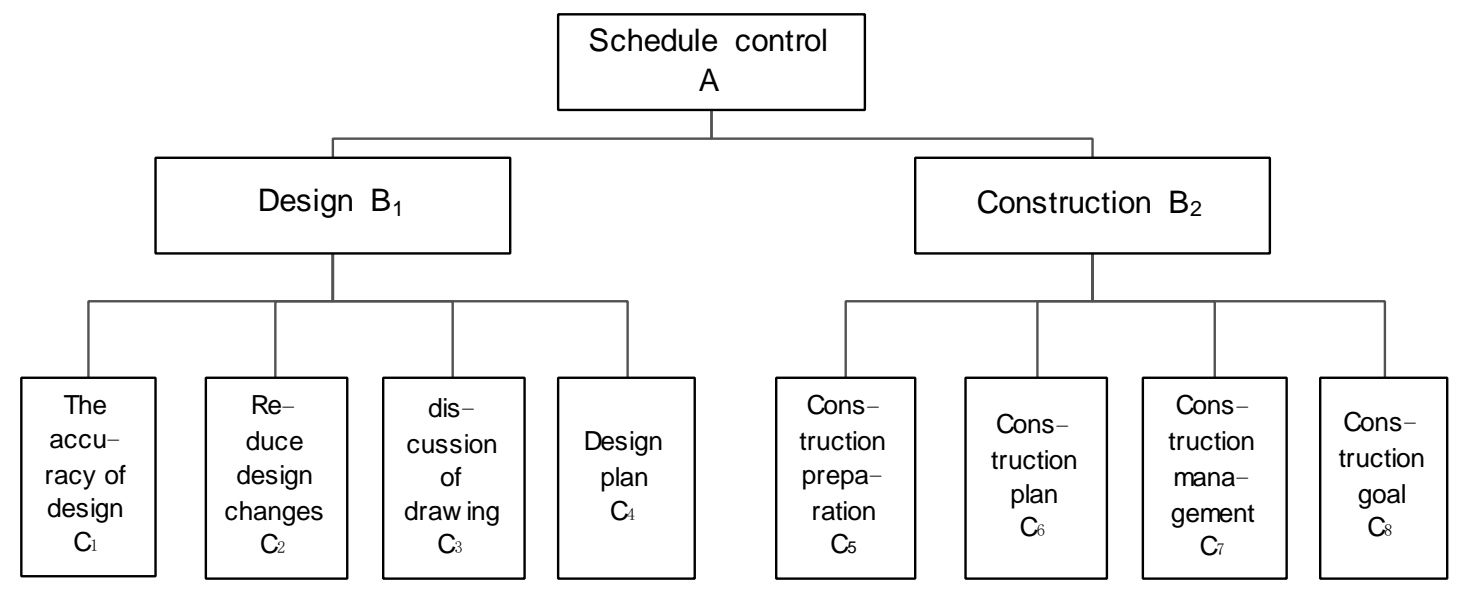

Figure 1 the hierarchical structure of the evaluation of the progress of the accounts

\section{Results and Discussions}

Then we can get judgment matrixes of various layers. Table 1 is the judgment matrixes of the A- 
B.

Table 1 The judgment matrixes of the A-B..

\begin{tabular}{|c|c|c|c|}
\hline $\mathrm{A}$ & $\mathrm{B}_{1}$ & $\mathrm{~B}_{2}$ & $\mathrm{~W}$ \\
\hline $\mathrm{B}_{1}$ & 1 & 2 & 0.667 \\
\hline $\mathrm{B}_{2}$ & $1 / 2$ & 1 & 0.333 \\
\hline
\end{tabular}

The numerical input AHP is obtained $\lambda \max =2.00$, C. R. $=0<0.1$, the consistency match the condition.

Table 2 is the judgment matrixes of the $\mathrm{B}_{1}-\mathrm{C}_{1-4}$.

Table 2 The judgment matrixes of the $\mathrm{B}_{1}-\mathrm{C}_{1-4}$.

\begin{tabular}{|c|c|c|c|c|c|}
\hline $\mathrm{B}_{1}$ & $\mathrm{C}_{1}$ & $\mathrm{C}_{2}$ & $\mathrm{C}_{3}$ & $\mathrm{C}_{4}$ & $\mathrm{~W}$ \\
\hline $\mathrm{C}_{1}$ & 1 & 4 & 2 & 3 & 0.472 \\
\hline $\mathrm{C}_{2}$ & $1 / 4$ & 1 & $1 / 2$ & $1 / 2$ & 0.108 \\
\hline $\mathrm{C}_{3}$ & $1 / 2$ & 2 & 1 & 2 & 0.256 \\
\hline $\mathrm{C}_{4}$ & $1 / 3$ & 2 & $1 / 2$ & 1 & 0.164 \\
\hline
\end{tabular}

The numerical input AHP is obtained $\lambda \max =4.05$, C. R. $=0.0172<0.1$, the consistency match the condition.

Table 3 is the judgment matrixes of the $\mathrm{B}_{2}-\mathrm{C}_{5-8}$.

Table 3 The judgment matrixes of the $\mathrm{B}_{2}-\mathrm{C}_{5-8}$.

\begin{tabular}{|c|c|c|c|c|c|}
\hline $\mathrm{B}_{2}$ & $\mathrm{C}_{5}$ & $\mathrm{C}_{6}$ & $\mathrm{C}_{7}$ & $\mathrm{C}_{8}$ & $\mathrm{~W}$ \\
\hline $\mathrm{C}_{5}$ & 1 & 2 & $1 / 2$ & 3 & 0.277 \\
\hline $\mathrm{C}_{6}$ & $1 / 2$ & 1 & $1 / 3$ & 2 & 0.160 \\
\hline $\mathrm{C}_{7}$ & 2 & 3 & 1 & 4 & 0.467 \\
\hline $\mathrm{C}_{8}$ & $1 / 3$ & $1 / 2$ & $1 / 2$ & 1 & 0.095 \\
\hline
\end{tabular}

The numerical input AHP is obtained $\lambda \max =4.03$, C. R. $=0.0116<0.1$, the consistency match the condition.

The judgment matrixes all match the condition. We can conclude that the weight of the each factors to the goal in table 4.

Table 4 The weight of the each factors to the goal.

\begin{tabular}{|c|c|}
\hline The factors in middle layer $\left(\mathbf{C}_{\mathbf{i}}\right)$ & weight \\
\hline construction management $\left(\mathrm{C}_{7}\right)$ & 0.311 \\
\hline construction preparation $\left(\mathrm{C}_{5}\right)$ & 0.185 \\
\hline the accuracy of designs $\left(\mathrm{C}_{1}\right)$ & 0.157 \\
\hline construction plan $\left(\mathrm{C}_{6}\right)$ & 0.107 \\
\hline discussion of drawing $\left(\mathrm{C}_{3}\right)$ & 0.085 \\
\hline construction goal $\left(\mathrm{C}_{8}\right)$ & 0.064 \\
\hline design plan $\left(\mathrm{C}_{4}\right)$ & 0.055 \\
\hline reduce design changes $\left(\mathrm{C}_{2}\right)$ & 0.036 \\
\hline
\end{tabular}

From the above analysis, in order to improve the level of schedule control, we can considered from three aspect: construction management, construction preparation, the accuracy of designs. We combined the project progress management thoughts and advanced means of information management, put forward the following three measures.

1) Broaden the channel of information exchange

At present, the construction project information relies mainly on the 2D drawings for storage, in the process of information transmission, the more and more cooperated-builing parties were join in 
the construction. In the process of information spread, there is the phenomenon we called information loss, and it maybe cause confliction. Reducing the level of information exchange and broadening the channel of information communication can reduce the conflict of project management. The current development of BIM technology, can establish the building information model to make management more efficient, and simplify the information level.

2) Prepare construction organization plan

To complete the project construction tasks we need to overcome many complex factors. We think the preparation of construction must be carried out seriously and carefully. To avoid the waste of people, goods, content, or even shut down the work, we should consider the construction task whether it is possibility or emergency. Many factors influence the construction progress of possibility, such as geology, hydrology, the weather will have different degrees of influence. In the process of doing the construction plan, we must consider from the whole life cycle, to strengthen the process control and possible problems and make the necessary preparations for construction.

3) Control the process of design stage

In the field of traditional design, the design concept of stylist mainly reflected by 2D drawings. In this way subjective imagination were added to the design. We can imagine that there is more difficult in some complex project to find the mistake through the physical model. 3DMAX and other 3D graphics software can be used for 3D visualization detection. More convenient construction data can be input BIM software, the virtual model can undertake collision detection, and we can avoid rework phenomenon caused by the design flaw. In this way we can improve the accuracy of the design, and make the construction more organized. The modeling BIM can be used throughout various stages especially in the planning, design, construction and operation.

\section{References}

[1] Ali Kokangül,Ulviye Polat,Cansu Dağsuyu.A new approximation for risk assessment using the AHP and Fine Kinney methodologies[J].Safety Science,2016.

[2] Elżbieta RadziszewskaZielina, Bartłomiej Szewczyk.Supporting Partnering Relation Management in the Implementation of Construction Projects Using AHP and Fuzzy AHP Methods [J] .Procedia Engineering,2016.

[3] B.Kittel,A.Kaczynski,S.Bethge,A.Mühlbacher.Was braucht der neue Landarzt? -Ein Analytic Hierarchy Process (AHP) [J].Gesundh ökon Qualmanag,2015. 